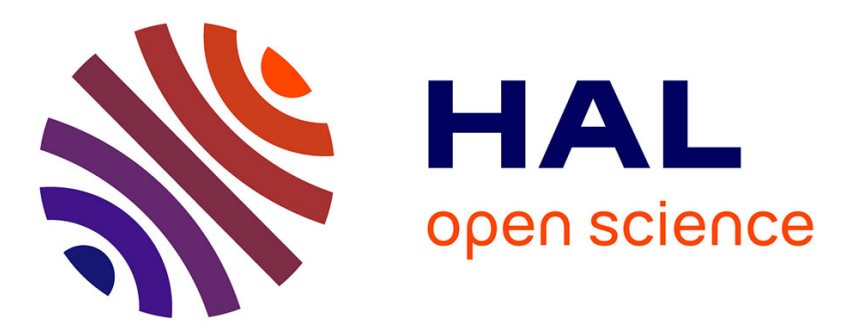

\title{
A two year investigation towards an effective quality control of incoming potatoes as an acrylamide mitigation strategy in French fries
}

Raquel C. Medeiros Vinci, Frédéric Mestdagh, Christof van Poucke, Carlos van Peteghem, Bruno de Meulenaer

\section{To cite this version:}

Raquel C. Medeiros Vinci, Frédéric Mestdagh, Christof van Poucke, Carlos van Peteghem, Bruno de Meulenaer. A two year investigation towards an effective quality control of incoming potatoes as an acrylamide mitigation strategy in French fries. Food Additives and Contaminants, 2011, pp.1. 10.1080/19440049.2011.639094 . hal-00762898

\section{HAL Id: hal-00762898 \\ https://hal.science/hal-00762898}

Submitted on 9 Dec 2012

HAL is a multi-disciplinary open access archive for the deposit and dissemination of scientific research documents, whether they are published or not. The documents may come from teaching and research institutions in France or abroad, or from public or private research centers.
L'archive ouverte pluridisciplinaire HAL, est destinée au dépôt et à la diffusion de documents scientifiques de niveau recherche, publiés ou non, émanant des établissements d'enseignement et de recherche français ou étrangers, des laboratoires publics ou privés. 


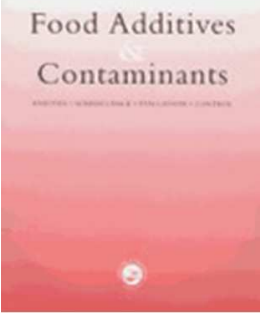

\section{A two year investigation towards an effective quality control of incoming potatoes as an acrylamide mitigation strategy in French fries}

\begin{tabular}{|c|c|}
\hline Journal: & Food Additives and Contaminants \\
\hline Manuscript ID: & TFAC-2011-378.R1 \\
\hline Manuscript Type: & Original Research Paper \\
\hline Date Submitted by the Author: & 28-Oct-2011 \\
\hline Complete List of Authors: & $\begin{array}{l}\text { C. Medeiros Vinci, Raquel; Ghent University, Department of Food Safety } \\
\text { and Food Quality } \\
\text { Mestdagh, Frédéric; Ghent University, Department of Food Safety and Food } \\
\text { Quality } \\
\text { Van Poucke, Christof; UGent, Laboratory of Food Analysis } \\
\text { Van Peteghem, Carlos; Ghent University, Pharmacy Department; UGent, } \\
\text { Laboratory of Food Analysis } \\
\text { De Meulenaer, Bruno; Ghent University, Department of Food Safety and } \\
\text { Food Quality }\end{array}$ \\
\hline Methods/Techniques: & Quality assurance \\
\hline Additives/Contaminants: & Acrylamide \\
\hline Food Types: & Potatoes, Processed foods \\
\hline Abstract: & $\begin{array}{l}\text { The current entrance quality control used in the French fries industry is } \\
\text { done based on colour evaluation with USDA/Munsell colour chart (after a } \\
\text { short frying test, typically } 180^{\circ} \mathrm{C} \text { for } 3 \text { min). Based on a study carried out } \\
\text { during } 2 \text { consecutive potato storage seasons the possibility of a more } \\
\text { effective entrance control of the raw potato tubers in order to identify } \\
\text { batches of potatoes prone to acrylamide formation was evaluated. The } \\
\text { current entrance control was compared to two other colour evaluation } \\
\text { methods (CIE L*a*b* colour parameters and a process-specific Agtron } \\
\text { analyzer) and to reducing sugar contents determination. Seasonal } \\
\text { variability did not affect the slopes of the linear correlation models, for } \\
\text { most of the parameters studied. The determination of colour formation } \\
\text { measured by the Agtron methodology and reducing sugars content allowed } \\
\text { a better identification of batches of potatoes prone to acrylamide formation } \\
\text { when compared to the current entrance control. Different scenarios } \\
\text { represented by decision trees for quality control measures for incoming } \\
\text { potatoes were evaluated while considering the investigation value of } 600\end{array}$ \\
\hline
\end{tabular}


$\mu \mathrm{g} \mathrm{kg}-1$ recently prescribed by the European Commission for French fries. Samples were categorized based on predictions of threshold values and acrylamide levels in the final product.

\section{SCHOLARONE ${ }^{m}$}

Manuscripts 


\section{A two year investigation towards an effective quality control of incoming potatoes as an acrylamide mitigation strategy in French fries}

Raquel Medeiros Vinci ${ }^{\mathrm{a}, \mathrm{b}}$, Frédéric Mestdagh ${ }^{\mathrm{a}, \mathrm{b}}$, Christof Van Poucke ${ }^{\mathrm{c}}$, Carlos Van Peteghem $^{\mathrm{c}}$, Bruno De Meulenaer ${ }^{\mathrm{a}, \mathrm{b}}$ *

${ }^{a}$ NutriFOODchem Unit, Department of Food Safety and Food Quality, Faculty of Bioscience Engineering, Ghent University, Coupure Links 653, B-9000 Ghent, Belgium; ${ }^{\mathrm{b}}$ Food2Know, Coupure Links 653, B-9000 Ghent, Belgium; ${ }^{\mathrm{c}}$ Laboratory of Food Analysis, Department of Bioanalysis, Faculty of Pharmaceutical Sciences, Ghent University, Harelbekestraat 72, B9000 Ghent, Belgium

* Corresponding author. Email address: Bruno.DeMeulenaer@UGent.be 


\section{Abstract}

The current entrance quality control used in the French fries industry is done based on colour evaluation with USDA/Munsell colour chart (after a short frying test, typically $180^{\circ} \mathrm{C}$ for 3 min). Based on a study carried out during 2 consecutive potato storage seasons the possibility of a more effective entrance control of the raw potato tubers in order to identify batches of potatoes prone to acrylamide formation was evaluated. The current entrance control was compared to two other colour evaluation methods (CIE L*a*b* colour parameters and a process-specific Agtron analyzer) and to reducing sugar content determination. Seasonal variability did not affect the slopes of the linear correlation models, for most of the parameters studied. The determination of colour formation measured by the Agtron methodology and reducing sugars content allowed a better identification of batches of potatoes prone to acrylamide formation when compared to the current entrance control. Different scenarios represented by decision trees for quality control measures for incoming potatoes were evaluated while considering the investigation value of $600 \mu \mathrm{g} \mathrm{kg}^{-1}$ recently prescribed by the European Commission for French fries. Samples were categorized based on predictions of threshold values and acrylamide levels in the final product.

KEYWORDS Acrylamide; Incoming potatoes; Quality control; Colour; Reducing sugars; French fries 


\section{Introduction}

2 Acrylamide is formed in starchy foods processed at high temperatures $\left(>120^{\circ} \mathrm{C}\right)$ commonly

3 applied in frying, baking and roasting (Tareke et al. 2002). This contaminant is mainly formed

4 through Maillard reactions between reducing sugars and specific amino acids such as asparagine

5 (Stadler et al. 2002; Mottram et al. 2002; Becalski et al. 2003). Potato products are strongly

6 susceptible to acrylamide formation since this food commodity contains asparagine and reducing

7 sugars. Because, the amount of free asparagine in potato tubers generally largely exceeds the

8 amount of reducing sugars; it is the latter which determines the degree of acrylamide formation

9 and Maillard browning upon frying (Amrein et al. 2003; De Wilde et al. 2005). Since the

10 discovery of acrylamide in foods, stakeholders have promptly supported the scientific community

11 in finding the mechanisms of acrylamide formation and possible mitigation strategies from farm-

12 to-fork. Food Drink Europe (CIAA/FDE) established a Technical Acrylamide Expert Group since

132003 and created the "Acrylamide Toolbox" which is available online

14 (www.fooddrinkeurope.eu). This toolbox presents a regularly updated description of the possible

15 mitigation strategies that could be employed to reduce acrylamide levels in foods contributing the

16 most for acrylamide intake (CIAA/FDE 2011). Nonetheless, acrylamide is still present in our

17 diets and moreover from a risk characterization perspective presents a very low MOE (margin of

18 exposure) (200-50) (FAO/WHO 2005). Consequently, regulatory authorities urge for the

19 reduction of acrylamide levels in food. Potato products, French fries in particular, are one of the

20 greatest contributors to dietary acrylamide intake (EFSA 2011). To date no legal limits regarding

21 acrylamide contents in foods have yet been established. Just recently, the European Commission

22 published a Recommendation on the website from the European Commission's Directorate

23 General for Health and Consumer Policy (DG SANCO) on investigations into the levels of

24 acrylamide in food (EC 2011). Member States are recommended to investigate cases where 
25 acrylamide contents of foodstuffs after final preparation, exceed prescribed acrylamide indicative 26 values. For French fries and potato crisps, these indicative values are 600 and $1000 \mu \mathrm{g} / \mathrm{kg}$, 27 respectively.

29 Current industrial practices in French fries production include an entrance quality control based 30 on colour evaluation with USDA/Munsell colour chart. Colour is evaluated after a short frying 31 test, typically $180^{\circ} \mathrm{C}$ for $3 \mathrm{~min}$. This quality control relates raw material to colour specifications 32 of final product (customers demand) and accordingly, either raw material is rejected for 33 processing or appropriate process adjustments are taken (e.g. blanching conditions). The ability 34 of the current entrance control to predict acrylamide formation in the final product was 35 previously compared to two other colour evaluation methods (CIE L*a*b* colour parameters and 36 a process-specific Agtron analyzer) and to reducing sugar contents determination (Medeiros 37 Vinci et al. 2010). Since multiple pre and post-harvest factors may impact acrylamide formation 38 in potato products (Amrein et al. 2003; Becalski et al. 2004; Elmore et al. 2007; Rommens et al. 39 2008; Shepherd et al. 2010), the study performed by Medeiros Vinci et al. (2010) was therefore 40 further elaborated in the following potato storage season. The goals were to evaluate if the 41 models observed in 2008 were still valid for another growth season and thus if a robust tool could 42 be identified which allows the industry to identify incoming potato lots which are more prone for 43 acrylamide formation during the final frying. This would allow French fries producers to take 44 appropriate measures in order to lower acrylamide contents in French fries as reasonably 45 possible. Different scenarios considering the possible quality control measures for incoming 46 potatoes were evaluated, categorizing samples based on predictions of threshold values and 47 acrylamide levels in the final product. 
49

50 Reagents and chemicals

51 All reagents and chemicals used for the acrylamide and sugar analysis were previously described

52 in Mestdagh et al. (2005) and De Wilde et al. (2005) respectively.

53

\section{Raw material}

55 Potato (Solanum tuberosum L.) varieties Bintje, Fontana and Asterix (Belgium); Russet Burbank, 56 Lady Olympia and Markies (The Netherlands), Innovator and Victoria (France); Agria 57 (Germany); and Maris Piper (UK) were used for the study (Medeiros Vinci et al. 2010). One lot 58 of each variety was supplied by a single producer to be studied throughout storage. All lots were 59 approved for frying according to the industry entrance control criteria (size above $50 \mathrm{~mm}$ and 60 minimal under water weight of $380 \mathrm{~g}$ ). Tubers were harvested in 2007 and 2008, treated with 61 CIPC and stored at $8^{\circ} \mathrm{C}$. Samples were taken on five different points in time (January-June) for 62 each storage season.

63 Fully refined palm oil (Cargill Refined Oils-Europe) was used for all the frying experiments.

64

65

66

67

\section{Preparation of French fries}

66 French fries were prepared as described in Medeiros Vinci et al. (2010). Briefly, thirty five potato tubers from each variety were peeled and cut into strips $(1 \mathrm{~cm} \times 1 \mathrm{~cm} \times 3 \mathrm{~cm})$ with a French friesshaped cutter. These, were washed with tap water for $1 \mathrm{~min}$, superficially dried on absorbent paper and divided into three groups. A first group, (entrance parameters) was fried at $180^{\circ} \mathrm{C}$ for 3 min. A second group (unblanched final parameters - 2Sf) was par-fried at $180^{\circ} \mathrm{C}$ for $90 \mathrm{~s}$, frozen overnight and fried at $175^{\circ} \mathrm{C}$ for $150 \mathrm{~s}$. The third group (blanched final parameters $-\mathrm{B} 1+2 \mathrm{Sf}$ ) included a blanching step $\left(70^{\circ} \mathrm{C}, 20 \mathrm{~min}\right.$, ratio potato/water of 1:5 (w:w)) prior to the par-frying 
73 step (as described for the unblanched). Frying and par-frying were conducted in a semi74 professional thermostated deep-fryer (Fritel 2505, Belgium). The repeatability of acrylamide 75 formation in French fries prepared according to these frying conditions presents a RSD of $15 \%$ 76 (Mestdagh et al. 2005).

77

78 Acrylamide analysis

79 Acrylamide was determined in homogenized potato sample as described previously (Mestdagh et 80 al. 2005). After aqueous extraction, using [2,3,3- $\left.\mathrm{D}_{3}\right]$ acrylamide as internal standard, the 81 acrylamide extract was further cleaned up by solid-phase extraction. The extract was analyzed 82 using LC-MS/MS with positive electrospray ionization.

\section{Sugar analysis}

84 Mono- and disaccharides in homogenized potato sample were assessed as described earlier (De

85 Wilde et al. 2005). Briefly, after aqueous extraction, addition of an internal standard (phenyl- $\beta$ 86 D-glucopyranoside), clean-up and drying under nitrogen, the filtrate was derivatized and injected 87 in a GC equipped with a flame-ionization detector.

\section{$88 \quad$ Analysis of dry matter}

89 The dry matter content was determined, based on an official AOAC method (1990). Briefly, $5 \mathrm{~g}$ 90 of homogenized potatoes were mixed with calcinated sea sand and placed in the oven at $105^{\circ} \mathrm{C}$ 91 until a constant weight was obtained.

93 Colour evaluation techniques

94 Colour of the French fries was determined using a Konica Minolta spectrophotometer CM-2500d 95 (Konica Minolta, Osaka, Japan), operating in the CIE L*a*b* colour space, an Agtron process 
96 analyzer (model E15-FP, Nevada, USA) and using an USDA/Munsell colour chart (VIVA, Den

97 Haag, The Netherlands), as described in Medeiros Vinci et al. (2010).

98

$99 \quad$ Statistical analysis

100 Pearson correlation analysis was performed using SPSS 17.0 (SPSS inc., Chicago, IL) to 101 determine linear relationships between different parameters studied and acrylamide. Significant 102 differences between slopes of linear models was accessed by Student t-test.

\section{Results and discussion}

105 Ten varieties of potato tubers from Western Europe, representing the most frequently used in 106 potato processing industry, were used for this study. Five sampling points were taken from 107 January to June in 2008 and repeated in 2009. Table 1 presents reducing sugar contents of the 10 108 potato varieties considered in this study during both sampling seasons and Figure 1 shows the 109 acrylamide contents of French fries prepared from the different potato varieties after blanching 110 and a two stage frying. Frying conditions were standard (par-fried at $180^{\circ} \mathrm{C}$ for $90 \mathrm{~s}$ and final 111 frying performed at $175^{\circ} \mathrm{C}$ for $150 \mathrm{~s}$ ) throughout all sampling points since e.g. moisture content 112 may greatly affect acrylamide and colour formation. As shown in Table 1, reducing sugar 113 contents of the 10 varieties sampled, varied throughout both seasons. Some varieties (e.g. 114 Asterix, Bintje and Fontana) tended to reach a higher reducing sugar content by the end of the 115 storage season, probably due to senescent sweetening. Remarkably, this was not observed for 116 Russet Barbank, a variety know to be particularly vulnerable for this phenomenon. For other 117 varieties however, no clear trend of the reducing sugar content could be observed, also probably 118 due to within batch variations. The variability of the raw material has previously been reported in 119 another study (De Meulenaer et al. 2008) and represents one of the challenges that potato growers 
120 and potato processing industry face every year in order to produce an end product with fixed 121 specifications for the customers. Climatic conditions prior to harvest of tubers and fertilization 122 level are some of the causes for such variability. Generally, a higher concentration of reducing 123 sugars in the raw material was observed in 2009 in comparison with 2008 (Table 1) and 124 consequently higher acrylamide contents were observed in 2009 (Figure 1). Moreover Table 1 125 shows that the standardized blanching conditions applied in this study resulted in average 126 removal of reducing sugar contents by $45-59 \%$ in 2008 and $13-50 \%$ in 2009 . This demonstrates 127 that besides the variation of reducing sugar content during both seasons, a difference in 128 leachability of these precursors under the applied standardized blanching conditions was also 129 observed. Therefore, the correlation models obtained for both cultivar seasons needed to be 130 compared in order to evaluate the feasibility of using an entrance control parameter for 131 acrylamide mitigation purposes.

133 Comparison of correlation models of 2008 and 2009 between reducing sugars content of the raw material, colour and acrylamide formation in French fries

135 Similar as for the dataset obtained for the season 2008 (Medeiros Vinci et al. 2010), the reducing 136 sugar content (both before and after blanching) and the color formation after different frying 137 procedures and using various assessment methods were correlated significantly with the 138 acrylamide content of the final product (Table 2). In both sampling seasons, entrance colour 139 parameters (after one stage frying, e.g. Agtron in 2008, R=0.83) correlated better to acrylamide in 140 the final product compared to reducing sugars in raw potato tubers $(\mathrm{R}=0.72)$. Figure 2 presents 141 the relationship between reducing sugars (A) and colour Agtron (B) with acrylamide for both 142 sampling seasons. As shown in this figure, a greater scattering of data points was observed for 143 reducing sugars when compared to the colour Agtron parameter. Moreover, from the perspective 
144 of possible industrial implementation, using a colour parameter as an acrylamide predictor in raw 145 material is more practical than analyzing sugar contents. Agtron was given as the example since 146 this was the colour parameter which generally presented higher correlation coefficients within all 147 different frying procedures (Table 2). This equipment is already typically used by French fries 148 industry for final product quality control. Thus, the current quality control of incoming potatoes, 149 can be improved towards acrylamide prediction by changing colour evaluation method from 150 USDA colour chart to the Agtron process analyzer.

152 Due the variability observed in raw material (Table 1), the correlation models obtained for both 153 cultivar seasons needed to be compared in order to evaluate the feasibility of using an entrance 154 control parameter as an acrylamide mitigation strategy. Accordingly, slopes of linear models 155 obtained for both seasons were compared statistically for significant differences by means of a $t$ 156 test with $95 \%$ confidence level (Table 2 ). The t values were calculated based on the difference 157 between the two slopes divided by the standard error of the difference between slopes. Slopes of 158 the correlation models obtained between entrance parameters and acrylamide in the final product 159 were not significantly different between both seasons with an exception of the models obtained 160 with the $\mathrm{a}^{*}$ parameter (Table 2). Models obtained between colour parameters after two stage 161 frying and acrylamide in the final product were not significantly different either. On the other 162 hand, significant differences were observed between slopes of the models regarding parameters 163 evaluated in the final product (reducing sugars after blanching and colour determination after 164 blanching and two stage frying). The models obtained with the $\mathrm{a}^{*}$ parameter were not 165 significantly different and therefore were an exception. The comparison of the correlation study 166 performed in 2008 and 2009 suggests that even though seasonal differences were observed 167 regarding the raw material used during both seasons, similar linear models were obtained for 
168 most of the parameters evaluated. This seems to be significantly relevant taking into account that 16910 different potato varieties were used and five sampling points were taken over a complete 170 storage season. In the previous study (Medeiros Vinci et al. 2010) the linear relationships 171 between the acrylamide content of the final product and the colour parameters considered or the 172 reducing sugar content were used, in combination with a hypothetical acrylamide limit, to define 173 threshold values (THVs) for the latter product parameters. This would enable the potato 174 processing industry to identify in a better way lots of potatoes which are prone to acrylamide 175 formation. This concept was again evaluated for the present dataset.

\section{The application of linear models and evaluation of threshold values (THVs)}

178 In contrast to our previous report (Medeiros Vinci et al. 2010) in which a hypothetical acrylamide 179 limit of $500 \mu \mathrm{g} \mathrm{kg}^{-1}$ was used, new threshold values were calculated based on the new EU 180 indicative level of $600 \mu \mathrm{g} \mathrm{kg}^{-1}$. Only the data of the parameters which presented linear models not 181 significantly different for both seasons were considered and thus they were combined in one data 182 set $(2008+2009)$ (Table 2) and THVs were determined for each relevant parameter on basis of 183 these combined datasets. In addition, the application of these THVs to the combined data-set 184 resulted in a preliminary analysis of sample categorization based on their predicted and actual 185 acrylamide levels in the final product (Table 3). For interpretation of the results, batches of 186 potatoes with acrylamide contents $<600 \mu \mathrm{g} \mathrm{kg}^{-1}$ are considered as "acceptable", while for 187 acrylamide contents $>600 \mu \mathrm{g} \mathrm{kg}^{-1}$ potato batches are considered as "unacceptable". In practice, 188 incoming potatoes that would be classified as "unacceptable" (within a certain limitation) would 189 not be necessarily rejected but rather subjected to a more rigorous blanching treatment. Samples 190 which are categorized as "acceptable" and have acrylamide $>600 \mu \mathrm{g} \mathrm{kg}^{-1}$ are considered as non191 conformities. On the other hand, samples which are categorized as "unacceptable" and 
192 containing acrylamide levels $<600 \mu \mathrm{g} \mathrm{kg}^{-1}$ would have been in conformity (in respect to the 193 acrylamide limit) but would represent unnecessary "extra-precautions for industry" (e.g., extra 194 blanching) which translates in unnecessary costs.

195

196 The comparison of the different entrance parameters demonstrated that the current method 197 applied as entrance control (USDA) would result in the highest percentage of rejected samples 198 (19\%) (Table 3). Worth noting is the fact that $56 \%$ of those rejected samples correspond to 199 samples "unnecessarily rejected", since the actual acrylamide content of the final product is lower 200 then the EU indicative level. Measuring colour with Agtron at entrance reduces the number of 201 rejected samples to $16 \%$ and in addition the number of "unnecessarily rejected" samples is 202 reduced to $40 \%$. The determination of reducing sugars at entrance allows even a further reduction 203 of rejected samples to $12 \%$, out of which, $37 \%$ are rejected "unnecessarily". This implies that 4, 6 204 and $11 \%$ of the samples would be unnecessarily rejected using the THV's for reducing sugars, 205 Agtron and USDA, respectively. Therefore the application of reducing sugars and Agtron could 206 represent a significant decrease in unnecessary costs that industry would have treating these 207 "unacceptable" potato lots, compared to a THV system based on the currently used USDA 208 measurement.

210 Another important aspect to consider when selecting a quality control parameter regarding 211 incoming potatoes, and when evaluating the THVs application is the percentage of non212 conformities, such as the percentage of accepted samples with acrylamide $>600 \mu \mathrm{g} \mathrm{kg}^{-1}$. These 213 percentages ranged from 1 to $3 \%$ for the entrance parameters (fried at $180^{\circ} \mathrm{C}, 3 \mathrm{~min}$ ) (Table 3 ). 214 The lowest percentage (1\%) was obtained with the application of the THV for Agtron. 
215 Determining reducing sugars at entrance or colour measurement with USDA would at least 216 double the percentage of accepted samples with acrylamide $>600 \mu \mathrm{g} \mathrm{kg}^{-1}$.

218 The application of THVs for colour parameters after two stage frying with and without blanching 219 was also analyzed regarding acrylamide prediction capability (Table 3). None of these parameters 220 showed further improvements regarding consumer safety (percentage of accepted samples with 221 acrylamide $>600 \mu \mathrm{g} \mathrm{kg}^{-1}$ ) or industry's "unnecessary costs" (percentage of rejected samples with 222 acrylamide $<600 \mu \mathrm{g} \mathrm{kg}^{-1}$ ) when compared to the entrance parameters above discussed. Moreover, 223 they represent a more elaborate handling during income control making them less appropriate to 224 be used in practice.

226 As a further elaboration of the THV concept, different scenarios considering the combination of 227 various entrance parameters were elaborated in order to investigate whether these would improve 228 the acrylamide prediction in the final product (Figure 3). For example, potato lots with a USDA 229 value $<2.3$ after the short frying test $\left(180^{\circ} \mathrm{C}, 3 \mathrm{~min}\right)$ would be accepted, while for USDA values $230>2.3$ samples would be submitted to colour evaluation with an Agtron process analyzer. For 231 Agtron values $>50$, potato lots would be accepted, while for Agtron values $<50$ samples would be 232 "rejected" or in other words additional precautions would be taken (e.g. extended blanching). The 233 same principle applies for the combinations Agtron/RS and USDA/RS. Results of acrylamide 234 prediction based on the different combinations of entrance parameters are presented in Table 3.

235 The application of the combined entrance control USDA/Agtron results in 93\% of correctly 236 categorized samples. Although no improvements were observed regarding the percentage of 237 correctly categorized samples in comparison with the application of Agtron (93\%) by itself, a 238 decrease in total rejected samples was observed from $16 \%$ to $13 \%$. This decrease resulted in a 
239 further reduction of the total "unnecessarily rejected" samples (from 6 to 5\%). However accepted 240 samples with acrylamide values $>600 \mu \mathrm{g} \mathrm{kg}^{-1}$ increased from $1 \%$ to $3 \%$ when applying Agtron 241 measurement individually versus the combined USDA/Agtron.

242

243 The combination Agtron/RS as an entrance control shows no improvements towards acrylamide 244 prediction when compared to the application of RS by itself. The application of the USDA/RS 245 combination as entrance control further decreased the percentage of rejected samples to $11 \%$, 246 although no improvements were found for the total "unnecessarily rejected" samples (4\%). 247 Furthermore, the application of the latest combination as entrance control resulted in an increase 248 of accepted samples with acrylamide $>600 \mu \mathrm{g} \mathrm{kg}^{-1}(4 \%)$. The combination USDA/Agtron/RS was 249 also tested and same results as USDA/RS were obtained.

250

251 It should be kept into account that the THV for quality control tools mentioned in this study are 252 directly related to the hypothetical acrylamide level of $600 \mu \mathrm{g} \mathrm{kg}^{-1}$ and thus are restricted to this 253 acrylamide limit, blanching and frying conditions used in this study. Moreover, dextrose and 254 sodium acid pyrophosphate which are typically added in industrial practices were not taken into 255 account in this correlation study. However, obtained results demonstrate that even though 256 seasonal variability was observed for the potato varieties used for this study, similar models were 257 obtained for both potato storage seasons. Consequently the determination of THVs as an entrance 258 control tool seems feasible, for standardized frying conditions. Moreover, from a food safety 259 point of view, a more optimal quality control could be adopted for incoming potatoes in order to 260 guarantee reduced acrylamide contents in the final product. Agtron measurement (after short 261 frying test) or determination of reducing sugars of the incoming product could provide a 262 preventive tool for French fry industry to evaluate the acrylamide problem at the start of the 
2

263 production process. Nevertheless, the application of Agtron measurements is certainly more 264 practical to implement and provides a better correlation to acrylamide in the final product 265 compared to reducing sugars determination in the raw material. The approach of combined 266 entrance parameters USDA/Agtron and Agtron/RS resulted in further decrease of "unnecessarily 267 rejected" samples. This may represent a significant decrease in costs related to unnecessary 268 precautions taken with lots of potatoes that would be "rejected". 269

270 For the future, a model describing the relationship between Agtron at entrance and Agtron of the 271 final product with acrylamide in the final product on an industrial scale could be established, and 272 applicable THVs determined. However due to several factors which might affect the models, 273 such as fries cut size, blanching, frying conditions, etc., further work is needed in order to 274 standardize all these variables. Nevertheless, this would allow industry a more effective entrance 275 control tool and moreover, the link between colour measurement and acrylamide of the final 276 product could replace the time consuming and expensive acrylamide analysis. 


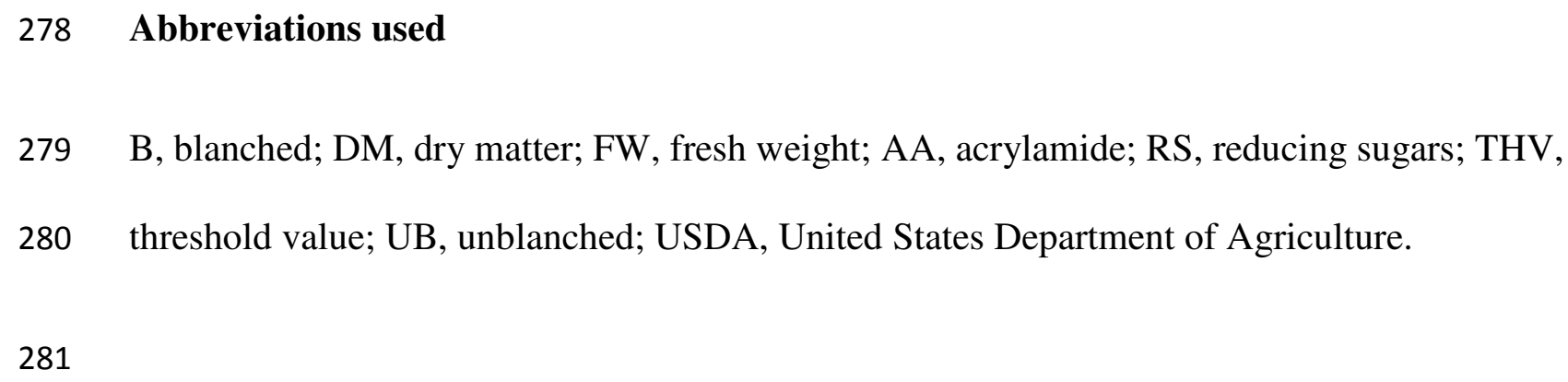

283 This research was financed by Flanders' FOOD, EPPA and Belgapom. Frédéric Mestdagh is a 284 post-doctoral researcher supported by the research Foundation-Flanders (FWO). The support 285 provided by PinguinLutosa Foods (Belgium) for the necessary practical arrangements was greatly 286 appreciated. The authors thank the steering committee of EUPPA for fruitful discussions during 287 editing of the manuscript. The authors thank Quenten Denon, Laurent De Smytere and Christel 288 Detavernier for technical assistance during lab analysis. 
290

291

292

293

294

295

296

297

298

299

300

301

302

303

304

305

306

307

308

309

310

311

312

313

314

\section{References}

Amrein, T.M., Bachmann, S., Noti, A., Biedermann, M., Barbosa, M.F., Biedermann-Brem, S., Grob, K., Keiser, A., Realini, P., Escher, F., and Amadò, R., 2003. Potential of acrylamide formation, sugars, and free asparagine in potatoes: A comparison of cultivars and farming systems. J.Agric.Food Chem. 51, 5556-5560.

AOAC, 1990. Association of Official Analytical Chemists. Moisture in animal feed. Official Methods of Analysis, 930.15, 15th Edition ed. AOAC, Gaithersburg, MD

Becalski, A., Lau, B.P.Y., Lewis, D., and Seaman, S.W., 2003. Acrylamide in foods: occurrence, sources, and modeling. J.Agric.Food Chem. 51, 802-808.

Becalski, A., Lau, B.P.Y., Lewis, D., Seaman, S.W., Hayward, S., Sahagian, M., Ramesh, M., and Leclerc, Y., 2004. Acrylamide in French fries: influence of free amino acids and sugars. J.Agric.Food Chem. 52, 3801-3806.

CIAA/FDE, Food Drink Europe Acrylamide Toolbox 2011, Available from: http://ec.europa.eu/food/food/chemicalsafety/contaminants/ciaa_acrylamide_toolbox09.pdf.

De Meulenaer, B., De Wilde, T., Mestdagh, F., Govaert, Y., Ooghe, W., Fraselle, S., Demeulemeester, K., Van Peteghem, C., Calus, A., Degroodt, J.M., and Verhé, R., 2008. Comparison of potato varieties between seasons and their potential for acrylamide formation. J.Sci.Food Agr. 88, 313-318.

De Wilde, T., De Meulenaer, B., Mestdagh, F., Govaert, Y., Vandeburie, S., Ooghe, W., Fraselle, S., Demeulemeester, K., Van Peteghem, C., Calus, A., Degroodt, J.M., and Verhé, R., 2005. Influence of storage practices on acrylamide formation during potato frying. J.Agric.Food Chem. 53, 6550-6557.

EC, European Commission Recommendation of 10 January 2011 on investigations into the levels of acrylamide in food, Available http://ec.europa.eu/food/food/chemicalsafety/contaminants/recommendation_10012011_acry lamide_food_en.pdf.

EFSA, Scientific Report of EFSA - Results on acrylamide levels in food from monitoring years 2007-2009 and exposure assessment, Available from: http://www.efsa.europa.eu/en/efsajournal/doc/2133.pdf

Elmore, J.S., Mottram, D.S., Muttucumaru, N., Dodson, A.T., Parry, M.A.J., and Halford, N.G., 2007. Changes in free amino acids and sugars in potatoes due to sulfate fertilization and the effcet on acrylamide formation. J.Agric.Food Chem. 55, 5363-5366.

FAO/WHO, Joint FAO/WHO Expert Committee on Food Additives: Summary and conclusions report from sixty-fourth meeting, Rome, 8-17 February 2005, Available from: http://www.who.int/ipcs/food/jecfa/summaries/en/index.htm. 
326 Medeiros Vinci, R., Mestdagh, F., De Muer, N., Van Peteghem, C., and De Meulenaer, B., 2010. 327 Effective quality control of incoming potatoes as an acrylamide mitigation strategy for the $328 \quad$ French fries industry. Food Addit.Contam. Part A 27, 417-425.

329 Mestdagh, F., De Meulenaer, B., Van Poucke, C., Detavernier, C., Cromphout, C., and Van 330 Peteghem, C., 2005. Influence of oil type on the amounts of acrylamide generated in a model 331 system and in French fries. J.Agric.Food Chem. 53, 6170-6174.

332 Mottram, D.S., Wedzicha, B.L., and Dodson, A.T., 2002. Acrylamide is formed in the Maillard 333 reaction. Nature 419, 448-449.

Rommens, C.M., Yan, H., Swords, K., Richael, C., and Ye, J.S., 2008. Low-acrylamide French fries and potato chips. Plant Biotechnol.J. 6, 843-853.

Shepherd, L.V.T., Bradshaw, J., Dale, M.F.B., McNicol, J.W., Pont, S.D.A., Mottram, D.S., and Davies, H.V., 2010. Variation in acrylamide producing potential in potato: Segregation of the trait in a breeding population. Food Chem. 123, 568-573.

Stadler, R.H., Blank, I., Varga, N., Robert, F., Hau, J., Guy, P.A., Robert, M.C., and Riediker, S., 2002. Acrylamide from Maillard reaction products. Nature 419, 449-450.

341 Tareke, E., Rydberg, P., Karlsson, P., Eriksson, S., and Törnqvist, M., 2002. Analysis of 342 acrylamide, a carcinogen formed in heated foodstuffs. J.Agric.Food Chem. 50, 4998-5006. 


\section{Figure captions}

347 Figure 1. Acrylamide contents of French fries prepared from different potato varieties in 2008 348 (represented in grey) and 2009 (represented in black) after blanching under standardized 349 conditions and two stage frying.

350

351 Figure 2. Relation between reducing sugar content in raw potatoes (A) and colour Agtron after 352 one stage frying (B) with acrylamide in French fries after blanching and two stage frying. Grey 353 triangles and broken line represent 2008 data and black squares and solid line 2009 represent the 354 data.

355

356 Figure 3. Possible combinations of different entrance parameters for acrylamide prediction in the 357 final product. RS expressed as $\mathrm{g} 100 \mathrm{~g}^{-1} \mathrm{FW}$. 


\section{Table captions}

362 Table 1. Dry matter (DM) of raw potato tubers and reducing sugar contents (RS) before (UB) and 363 after standardized blanching treatment (B) for different potato varieties throughout 2008 and 3642009 potato storage seasons.

365

366 Table 2. Pearson correlation coefficients (R) and slopes of linear models obtained in correlation 367 studies of 2008, 2009 and combined data 2008+2009. Parameters: entrance (reducing sugars-raw 368 material; colour- after one stage frying); non blanched-two stage fried (2 Sf) (colour); blanched369 two stage fried $(\mathrm{Bl}+2 \mathrm{Sf})$ (reducing sugars-blanched potato strips; colour-after blanching and 370 two stage frying).

371

372 Table 3. Application of THVs of data $2008+2009$ and an acrylamide limit of $600 \mu \mathrm{g} / \mathrm{kg}$ to 373 samples of the study $(2008+2009)$ regarding acrylamide formation in French fries. RS expressed 374 as g/100 g FW. Parameters: entrance (reducing sugars-raw material; colour- after one stage 375 frying); non blanched-two stage fried (2 Sf) (colour); blanched-two stage fried (B1 $+2 \mathrm{Sf})$ 376 (reducing sugars-blanched potato strips; colour-after blanching and two stage frying). 


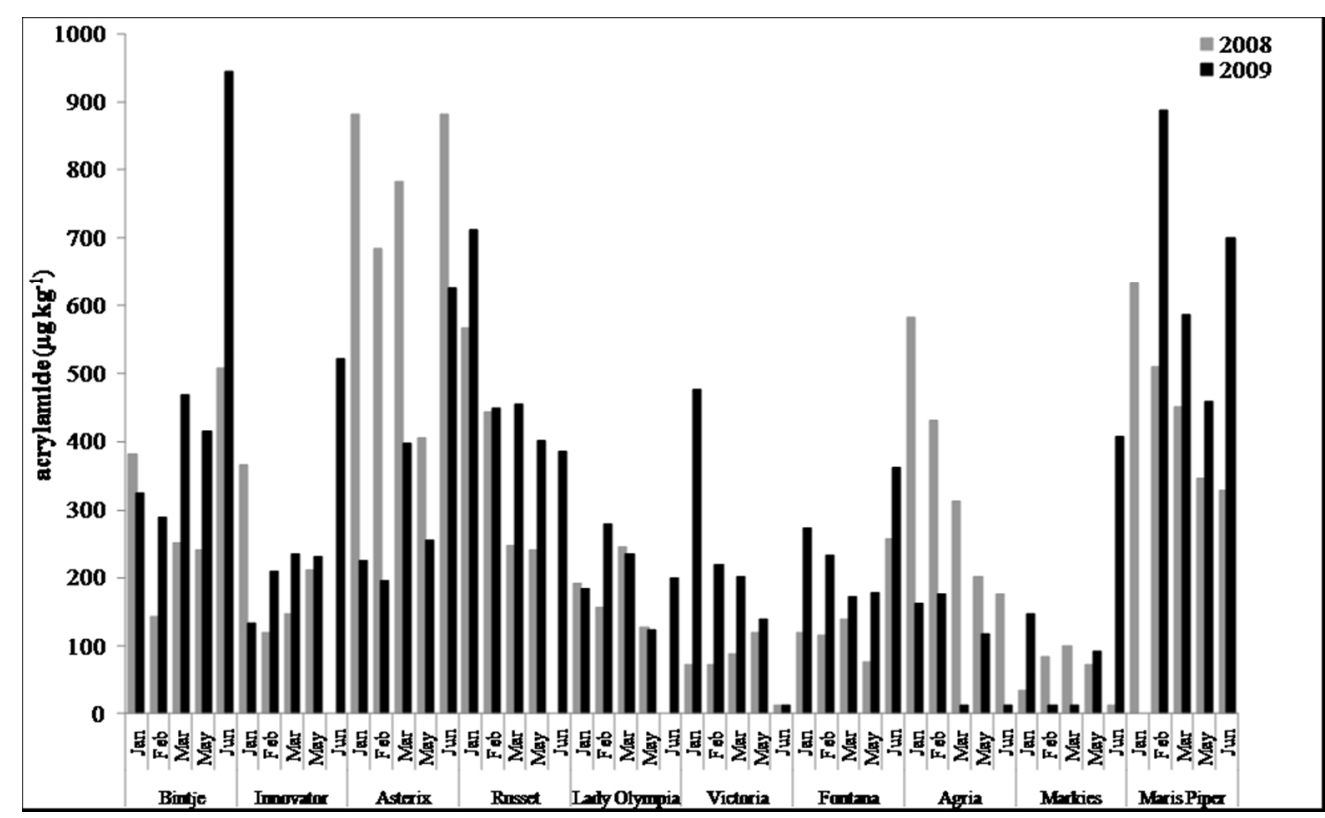

$259 \times 157 \mathrm{~mm}(96 \times 96 \mathrm{DPI})$ 
Relation between reducing sugar content in raw potatoes (A) and colour Agtron after one stage frying (B) with acrylamide in French fries after blanching and two stage frying. Grey triangles and broken line represent 2008 data and black squares and solid line 2009 represent the data. $362 \times 121 \mathrm{~mm}(96 \times 96 \mathrm{DPI})$ 


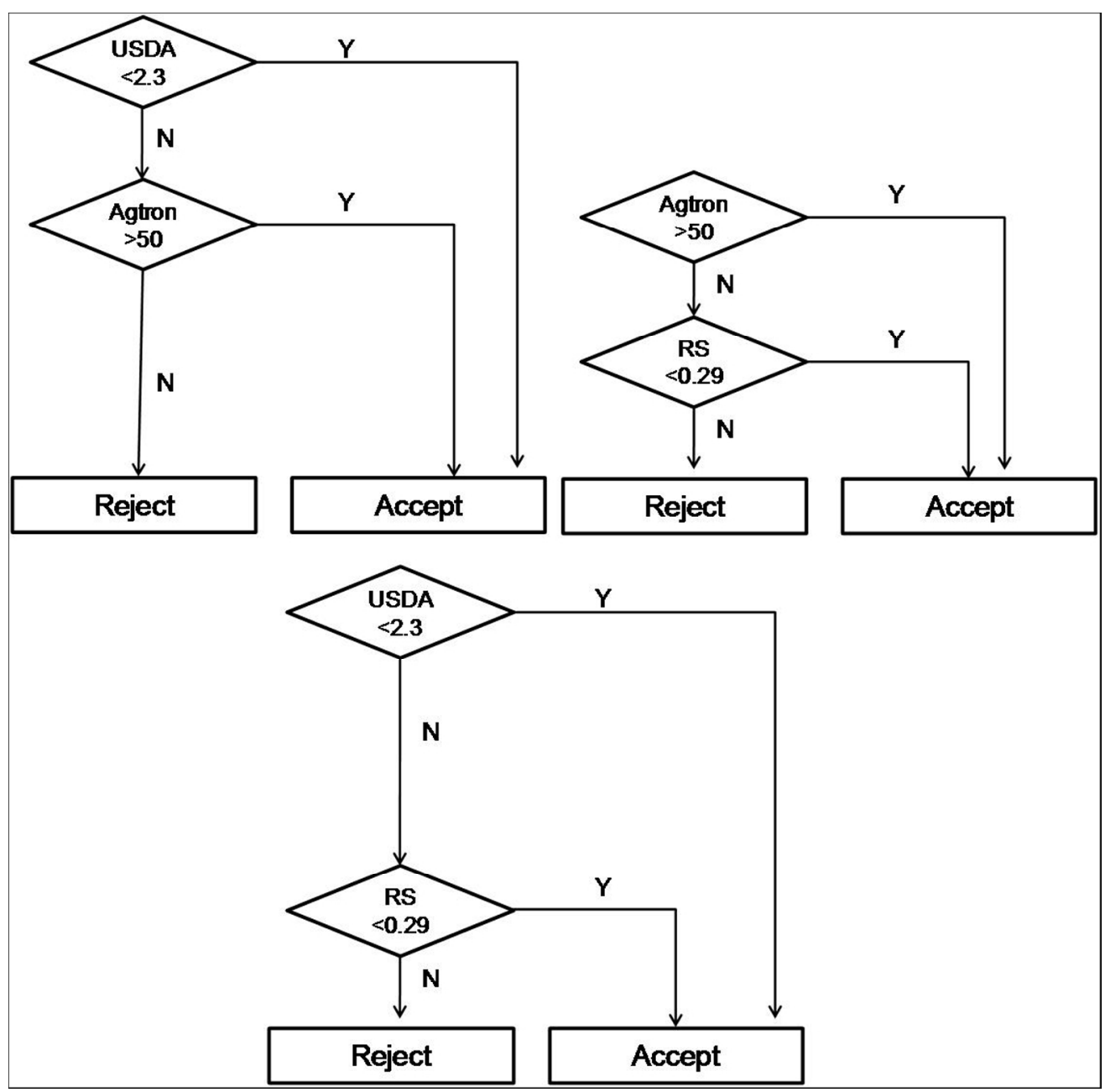

Possible combinations of different entrance parameters for acrylamide prediction in the final product. RS expressed as g $100 \mathrm{~g}-1 \mathrm{FW}$. $239 \times 236 \mathrm{~mm}(120 \times 120 \mathrm{DPI})$ 
Table 1

\begin{tabular}{|c|c|c|c|c|c|c|c|c|c|c|c|c|c|}
\hline & & & & $\begin{array}{l}\text { Maris } \\
\text { Piper }\end{array}$ & Asterix & Bintje & $\begin{array}{c}\text { Russet } \\
\text { Burbank }\end{array}$ & Innovator & Agria & Victoria & Fontana & $\begin{array}{c}\text { Lady } \\
\text { Olympia }\end{array}$ & Markies \\
\hline \multirow[t]{11}{*}{2008} & & $\operatorname{DM}(\%)^{\mathrm{a}}$ & & $20.7 \pm 3.0$ & $19.4 \pm 1.3$ & $20.9 \pm 2.2$ & $20.5 \pm 1.7$ & $21.6 \pm 1.1$ & $19.3 \pm 1.0$ & $16.6 \pm 0.9$ & $19.7 \pm 2.6$ & $19.4 \pm 1.9$ & $20.2 \pm 2.1$ \\
\hline & \multirow[t]{2}{*}{ Jan } & $\mathrm{RS}\left(\mathrm{g} 100 \mathrm{~g}^{-1} \mathrm{FW}\right)$ & UB & 0.35 & 0.37 & ND & 0.21 & 0.133 & 0.12 & ND & ND & ND & ND \\
\hline & & & B & 0.19 & 0.17 & 0.07 & 0.15 & 0.07 & 0.03 & ND & ND & ND & ND \\
\hline & \multirow[t]{2}{*}{ Feb } & & UB & 0.28 & 0.27 & ND & 0.19 & 0.17 & 0.14 & 0.05 & 0.04 & 0.05 & 0.03 \\
\hline & & & B & 0.24 & 0.12 & 0.04 & 0.07 & 0.05 & 0.11 & 0.02 & 0.04 & 0.02 & 0.02 \\
\hline & \multirow[t]{2}{*}{ Mar } & & UB & 0.33 & 0.32 & 0.11 & 0.19 & 0.12 & 0.17 & 0.04 & 0.03 & 0.05 & 0.01 \\
\hline & & & B & 0.17 & 0.14 & 0.06 & 0.05 & 0.04 & 0.06 & 0.02 & 0.01 & 0.03 & 0.01 \\
\hline & \multirow[t]{2}{*}{ May } & & UB & 0.25 & 0.25 & 0.16 & 0.06 & 0.19 & 0.08 & 0.03 & 0.03 & 0.02 & 0.02 \\
\hline & & & B & 0.11 & 0.07 & 0.07 & 0.04 & 0.08 & 0.05 & 0.02 & 0.01 & 0.01 & 0.01 \\
\hline & \multirow[t]{2}{*}{ Jun } & & UB & 0.50 & 0.50 & 0.36 & ND & ND & 0.10 & 0.10 & 0.14 & ND & 0.03 \\
\hline & & & B & 0.21 & 0.22 & 0.25 & ND & ND & 0.04 & 0.07 & 0.08 & ND & 0.02 \\
\hline \multirow[t]{11}{*}{2009} & & $\mathrm{DM}(\%)^{\mathrm{a}}$ & & $18.8 \pm 1.9$ & $18.2 \pm 2.3$ & $20.6 \pm 3.0$ & $20.8 \pm 3.0$ & $18.7 \pm 2.7$ & $19.7 \pm 2.7$ & $17.7 \pm 3.5$ & $20.6 \pm 1.1$ & $20.2 \pm 2.2$ & $19.0 \pm 2.1$ \\
\hline & \multirow[t]{2}{*}{ Jan } & $\mathrm{RS}\left(\mathrm{g} 100 \mathrm{~g}^{-1} \mathrm{FW}\right)$ & UB & ND & 0.13 & 0.11 & 0.23 & 0.04 & 0.02 & 0.10 & 0.07 & 0.05 & 0.01 \\
\hline & & & B & ND & 0.07 & 0.08 & 0.12 & 0.04 & 0.02 & 0.07 & 0.06 & 0.04 & 0.01 \\
\hline & \multirow[t]{2}{*}{ Feb } & & UB & 0.47 & 0.14 & 0.14 & 0.18 & 0.09 & 0.03 & 0.08 & 0.04 & 0.16 & 0.02 \\
\hline & & & B & 0.21 & 0.05 & 0.09 & 0.15 & 0.04 & 0.02 & 0.04 & 0.03 & 0.03 & 0.01 \\
\hline & \multirow[t]{2}{*}{ Mar } & & UB & 0.56 & 0.10 & 0.12 & 0.09 & 0.08 & 0.02 & 0.05 & 0.07 & 0.03 & 0.02 \\
\hline & & & B & 0.34 & 0.08 & 0.09 & 0.08 & 0.05 & 0.01 & 0.03 & 0.05 & 0.02 & 0.01 \\
\hline & \multirow[t]{2}{*}{ May } & & UB & 0.43 & 0.25 & 0.25 & 0.17 & 0.15 & 0.03 & 0.05 & 0.09 & 0.04 & 0.06 \\
\hline & & & B & 0.26 & 0.06 & 0.1 & 0.12 & 0.06 & 0.01 & 0.03 & 0.05 & 0.02 & 0.01 \\
\hline & \multirow[t]{2}{*}{ Jun } & & UB & 0.49 & 0.50 & 0.40 & 0.15 & 0.23 & 0.03 & 0.03 & 0.17 & 0.04 & 0.29 \\
\hline & & & B & 0.31 & 0.16 & 0.28 & 0.15 & 0.17 & 0.03 & 0.02 & 0.09 & 0.04 & 0.17 \\
\hline
\end{tabular}

${ }^{\mathrm{a}}$ Mean $\pm \mathrm{SD}$ of dry matter contents of raw potato tubers throughout 2008 and 2009. ND - not determined. 
Table 2.

\begin{tabular}{|c|c|c|c|c|c|c|c|}
\hline & & \multicolumn{2}{|c|}{2008} & \multicolumn{2}{|c|}{2009} & \multicolumn{2}{|c|}{$2008+2009$} \\
\hline & & $\mathrm{R}$ & Slope & $\mathrm{R}$ & Slope & $\mathrm{R}$ & Slope \\
\hline \multirow{4}{*}{ Entrance } & RS (g $\left.100 \mathrm{~g}^{-1} \mathrm{FW}\right)$ & 0.72 & 0.00047 & 0.82 & 0.00053 & 0.81 & 0.00048 \\
\hline & Agtron & -0.83 & -0.0509 & -0.91 & -0.0589 & -0.87 & -0.05487 \\
\hline & USDA & 0.74 & 0.00301 & 0.86 & 0.00372 & 0.78 & 0.00332 \\
\hline & $a^{*}$ & 0.77 & $0.00748^{a}$ & 0.87 & $0.0112^{\mathrm{a}}$ & N/A & $\mathrm{N} / \mathrm{A}$ \\
\hline \multirow{3}{*}{$2 \mathrm{Sf}$} & Agtron & -0.81 & -0.0533 & -0.91 & -0.0567 & -0.85 & -0.0539 \\
\hline & USDA & 0.72 & 0.0030 & 0.77 & 0.0029 & 0.68 & 0.0028 \\
\hline & $a^{*} \quad \square$ & 0.82 & 0.0091 & 0.89 & 0.0107 & 0.82 & 0.0093 \\
\hline \multirow{4}{*}{$\mathrm{Bl}+2 \mathrm{Sf}$} & $\mathrm{RS}\left(\mathrm{g} 100 \mathrm{~g}^{-1} \mathrm{FW}\right)$ & 0.78 & $0.00022^{a}$ & 0.84 & $0.00031^{\mathrm{a}}$ & N/A & N/A \\
\hline & Agtron & -0.88 & $-0.0420^{a}$ & -0.88 & $-0.0298^{a}$ & $\mathrm{~N} / \mathrm{A}$ & $\mathrm{N} / \mathrm{A}$ \\
\hline & USDA & 0.68 & $0.00305^{\mathrm{a}}$ & 0.49 & $0.00108^{\mathrm{a}}$ & N/A & $\mathrm{N} / \mathrm{A}$ \\
\hline & $a^{*}$ & 0.80 & 0.00691 & 0.92 & 0.00670 & 0.85 & 0.00678 \\
\hline
\end{tabular}

${ }^{a}$ Slopes significantly different, $(\mathrm{p}<0.05)$ for models obtained in 2008 and 2009. N/A - not applicable. 
Table 3.

\begin{tabular}{|c|c|c|c|c|c|c|c|}
\hline & & & Acce & ted samples & Reje & ted samples & \\
\hline & ameter & THV & $\begin{array}{c}\text { total } \\
\text { accepted }^{\mathrm{a}}\end{array}$ & $\begin{array}{l}\text { accepted and AA } \\
>600 \mathrm{ug} \mathrm{kg}^{-1 \mathrm{~b}}\end{array}$ & $\begin{array}{c}\text { total } \\
\text { rejected }^{\mathrm{a}}\end{array}$ & $\begin{array}{l}\text { rejected and AA } \\
<600 \mathrm{ug} \mathrm{k}^{-1 \mathrm{c}}\end{array}$ & $\begin{array}{c}\text { Correctly } \\
\text { categorized }\end{array}$ \\
\hline Entrance & $\mathrm{RS}$ & $>0.29$ & 88.2 & 2.4 & 11.8 & 36.4 & 93.5 \\
\hline & Agtron & $<50$ & 84.4 & 1.2 & 15.6 & 40.0 & 92.7 \\
\hline & USDA & $>2.3$ & 81.3 & 2.6 & 18.8 & 55.6 & 87.5 \\
\hline & USDA/Agtron & & 87.1 & 2.5 & 12.9 & 41.7 & 92.5 \\
\hline & Agtron/RS & & 88.2 & 2.4 & 11.8 & 36.4 & 93.5 \\
\hline & USDA/RS & & 89.2 & 3.6 & 10.8 & 40.0 & 92.5 \\
\hline $2 \mathrm{Sf}$ & Agtron & 41 & 84.4 & 2.5 & 15.6 & 46.7 & 90.6 \\
\hline & USDA & 2.5 & 83.3 & 5.0 & 16.7 & 62.5 & 85.4 \\
\hline & $a^{*}$ & 5.7 & 83.3 & 3.8 & 16.7 & 56.3 & 87.5 \\
\hline $\mathrm{Bl}+2 \mathrm{Sf}$ & $a^{*}$ & 2.6 & 86.5 & 4.8 & 13.5 & 53.8 & 88.5 \\
\hline
\end{tabular}

${ }^{a}$ Percentage calculated based on total number of samples $(2008+2009), \mathrm{N}=93 ;{ }^{\mathrm{b}}$ Percentage calculated based on accepted samples when applying investigation value for acrylamide and THV for the respective parameter; ${ }^{\mathrm{c}}$ Percentage calculated based on rejected samples when applying investigation value for acrylamide and THV for the respective parameter. 